\title{
MUCOSAL MAST CELLS IN IRRITABLE BOWEL SYNDROME AND INFLAMMATORY BOWEL DISEASE
}

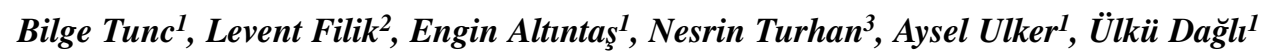 \\ Turkiye Yuksek Ihtisas Hospital, Ankara, Turkey: Gastroenterology Clinic ${ }^{1}$, Division of Pathology ${ }^{3}$; Başkent University, Faculty \\ of Medicine, Ankara, Turkey: Department of Gastroenterology ${ }^{2}$
}

\begin{abstract}
Summary: Even though exciting progresses have been until now, further studies are necessary to clearly understand the significance of MMC. Mast cells are thought to participate in the pathogenesis of inflammatory bowel disease and irritable bowel syndrome. However, their role in the pathogenesis remains unsettled. The specific aims of this study were to (1) examine mucosal mast cell counts in the cecum in patient with IBS, and IBD (2) compare MMC between the disease groups. We showed increased MMC count in IBS.
\end{abstract}

Key words: Mast cell; Inflammatory bowel disease; Irritable bowel syndrome

\section{Introduction}

Mast cells are thought to participate in the pathogenesis of inflammatory bowel disease (IBD) and irritable bowel syndrome (IBS) (1-3). However, their role in the pathogenesis remains unsettled. The specific aims of this study were to (1) examine mucosal mast cell (MMC) counts in the caecum in patient with IBS, and IBD (2) compare MMC between the disease groups.

\section{Methods}

Patients: Patients with histologically confirmed IBD (ulcerative colitis $(n=4)$, Crohn's disease $(n=1)$ ), and patients with IBS $(n=11)$ and normal control patients $(n=5)$ were included in that study. The diagnosis of IBS is made by the presence of symptoms delineated in the Manning and Rome criteria in the absence of organic disease $(4,5)$.

Histologic examination: Biopsy specimens were obtained from the caecum of each patient. The biopsy specimens were fixed in $10 \%$ formalin, routinely processed, and then embedded in paraffin. Using a standart microtome, each biopsy was sectioned $5-\mu \mathrm{m}$ cuts followed by staining with hematoxylin and eosin and toluidine blue. All mast cell counts were performed on the same microscope (Nikon Alphaphot-2) using 1000X magnification by a single pathologist unaware of the clinical diagnosis. Ten microscope fields per biopsy were examined to quantify mucosal mast cells.

Statistical analysis: Age, sex and mean mast cell numbers were analyzed with Kruskal-Wallis variance analysis. Mann-
Whitney-U test was used to analyse the age, sex matched mast cell numbers. $\mathrm{P}$ value $<0.05$ was predicted as significant.

\section{Results}

Tho control patients consisted of three males and two females, ages ranging from 33 to 74 years (mean $=50.4 \pm$ 18.3). There were 11 IBS patients, 8 males and 3 females whose age ranged from 27 to 64 years $($ mean $=46.4 \pm 16.5)$. There were 5 IBD patients (four of them were ulcerative colitis; one of them was Crohn's disease), 4 males and 1 female whose age ranged from 33 to 57 years (mean = 41.6 \pm 9.8 ). There was no statistically significant difference in the ages and genders between IBD; IBS and control groups. The hematoxylin and eosin stained pathological specimens revealed edematous mucosa in IBS and control groups, whereas active colitis in IBD patients. The MMC counts were $39.3 \pm 11.2$ in IBS patients, $22.2 \pm 4.2$ in IBD patients and 13.2 \pm 1.9 in control groups (Table 1). The MMC number was significantly higher in IBS patient than IBD patients $(p<0.01)$ and then control group $(p<0.001)$. The MMC number was significantly higher in IBD patients than control patients $(\mathrm{p}<0.01)$.

\section{Discussion}

In that study, we showed increased MMC count in IBS. Mast cells are an important source of tumor necrosis factor alpha which is an important mediator in several inflammatory disorders. Winterkamp et al. showed that there is 
Tab. 1: The MMC counts, genders and ages in patients.

\begin{tabular}{|c|c|c|c|c|c|c|c|c|}
\hline \multicolumn{3}{|c|}{ IBS patients } & \multicolumn{3}{|c|}{ IBD patients } & \multicolumn{3}{|c|}{ Control } \\
\hline Age & Gender & $M M C$ count & Age & Gender & MMC count & Age & Gender & $M M C$ count \\
\hline 37 & $\mathrm{M}$ & 41 & $57 \mathrm{yr}$ & M & 25 & $33 \mathrm{yr}$ & $\mathrm{F}$ & 11 \\
\hline 37 & $\mathrm{M}$ & 28 & $45 \mathrm{yr}$ & $\mathrm{F}$ & 23 & $39 \mathrm{yr}$ & $\mathrm{M}$ & 16 \\
\hline 81 & $M$ & 35 & $33 \mathrm{yr}$ & $\mathrm{M}$ & 19 & $66 \mathrm{yr}$ & $\mathrm{F}$ & 14 \\
\hline 60 & $\mathrm{M}$ & 42 & $39 \mathrm{yr}$ & $\mathrm{M}$ & 27 & $74 \mathrm{yr}$ & $\mathrm{M}$ & 12 \\
\hline 59 & $\mathrm{M}$ & 27 & $34 \mathrm{yr}$ & $\mathrm{M}$ & 17 & $40 \mathrm{yr}$ & $\mathrm{M}$ & 13 \\
\hline 31 & $\mathrm{M}$ & 44 & & & & & & \\
\hline 23 & $\mathrm{~F}$ & 36 & & & & & & \\
\hline 39 & $\mathrm{M}$ & 64 & & & & & & \\
\hline 37 & $\mathrm{~F}$ & 52 & & & & & & \\
\hline 53 & $\mathrm{M}$ & 29 & & & & & & \\
\hline 53 & $\mathrm{~F}$ & 34 & & & & & & \\
\hline
\end{tabular}

a strong correlation between urinary methyl histamine a mast cell product and endoscopic severity and inflammation. They stated that stress can increase gut permeability, increase ion secretion by a mechanism involving neural stimulation or mast cells, increase mucin release and deplete goblet cells (3). Stress causes parasympathetic activation ultimately affecting mucosal mast cells. As a result of these changes luminal antigens may gain access to the epithelium, causing inflammation. In contrast, Fukumoto et al. demostrated that mast cells were not essential in the development of sulfonic acid induced colitis in rats (5). The role of mast cells in Crohn's disease remains to be established. Santos et al. stated that chronic stress caused an epithelial barrier defect and epithelial mitochondrial damage, in parallel with mucosal mast cell hyperplasia and activation (6-9). Stoyanova et al. declared that interactions between neuronal elements and mast cells play a significant role in the progress and maintenance of inflammatory bowel processes in ulcerative colitis (4). The observations that IBS may be precipitated by an acute enteric infection, or occurs commonly in patients in remission from IBD has prompted consideration of inflammation as a putative basis for symptom generation in IBS (8). With better techniques to study mast cell function it has become clear that these cells may have a much wider role in immune responses and regulation than previously recognized. Even though exciting progresses have been until now, further studies are necessary to clearly understand the significance of MMC.

\section{References}

1. Manning AP, Thompson WG, Heaton $\mathrm{KW}$ et al. Toward positive diagnosis of irritable bowel. Br Med J 1978;32:334-6.

2. Thompson WG, Creed F, Drossman DA, et al. Functional bowel disease and functional abdominal pain. Gastroenterol Int 1992;5:75-91.

3. Winterkamp S, Weidenhiller M, Otte $\mathrm{P}$ et al. Urinary excretion of N-methyl histamine as a marker of disease activity in inflammatory bowel disease. Am J Gastroenterol 2002;97(12):3071-7.

4. Stoyanova II, Glubova MV. Mast cells and inflammatory mediators in chronic ulcerative colitis. Acta Histochem 2002;104(2):185-92.

5. Fukumoto Y, Kasai H, Takahashi $\mathrm{H}$ et al. The role of mast cells in the development of 2, 4, 6-trinitrobenzene sulfonic acid-induced colitis in rats. Scand J Gastroenterol 2002;37(5):555-60.

6. Santos J, Yang PC, Soderholm JD, Benjamin M, Perdue MH. Role of mast cells in chronic stress induced colonic epithelial barrier dysfunction in the rat. Gut 2001;48(5):630-6

7. MacDermott RP. Alterations in the mucosal immune system in ulcerative colitis and Crohn's disease. Med Clin North Am 1994;78:1207.

8. Collins SM, Vallance B, Barbara G, Borgaonkar M. Putative inflammatory and immunological bowel mechanisms in functional bowel disorders. Bailieres Best Pract Res Clin Gastroenterol 1999;13(3):429-36.

9. Higa A, Ishikawa N, Eto T, Nawa Y. Evaluation of the role of mast cells in the progression of acetic acid induced colitis in mice. Scand $\mathrm{J}$ Gastroenterol 1996;31(8):774-7.

Submitted June 2005.

Accepted August 2005.

Dr. Levent Filik,

Başkent Üniversitesi, Tip Fakültesi,

Gastroenteroloji Bölümü, Bahçelievler, Ankara, 06600,

Turkey.

e-mail: leventfilik@yahoo.co.uk 